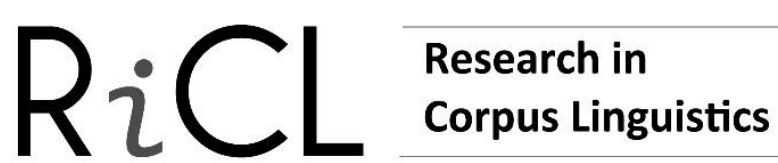

\section{Changes in argument structure in Early Modern English with special reference to verbs of DESIRE: A case study of lust}

\author{
Noelia Castro-Chao \\ University of Santiago de Compostela / Spain
}

\begin{abstract}
In Old and Middle English, several verbs of DESIRE could be found in impersonal constructions, a type of morphosyntactic pattern which lacks a subject marked for the nominative case controlling verbal agreement. The impersonal construction began to decrease in frequency between 1400 and 1500 (van der Gaaf 1904; Allen 1995), a development which has been recently investigated from the perspective of the interaction between impersonal verbs and constructional meaning by Trousdale (2008), Möhlig-Falke (2012) and Miura (2015). This paper is concerned specifically with the impersonal verb lust (< ME lusten) as a representative of Levin's (1993) class of verbs of DESIRE, some of which developed into prepositional verbs in Present-day English. The main aim here is to explore the changes undergone by lust during the two centuries after it ceases to appear in impersonal constructions, as well as to reflect upon some of the possible motivations for such changes. The data are retrieved from Early English Books Online Corpus 1.0, a 525-millionword corpus, and the examples are analysed manually paying attention to the range of complementation patterns documented in Early Modern English (1500-1700).
\end{abstract}

Keywords - argument structure; corpus linguistics; Early Modern English; impersonal construction; impersonal verb; verbs of DESIRE

\section{INTRODUCTION ${ }^{1}$}

The present paper explores the historical development of the verb lust in Early Modern English (1500-1700; henceforth EModE), a member of the class of verbs of DESIRE as defined in Levin (1993: 194-195) in her discussion of Present-day English (henceforth PDE) patterns of verb alternation. Verbs of DESIRE include, among others, formerly

\footnotetext{
${ }^{1}$ For generous financial support, I am grateful to the following institutions: the Spanish Ministry of Education (grant FPU2014/03208), the European Regional Development Fund, the Spanish Ministry of Science, Innovation and Universities (grant FFI2017-86884-P) and the Regional Government of Galicia (Directorate General for Scientific and Technological Promotion, grants ED431D 2017/09 and ED431B 2017/12). Thanks are also due to Teresa Fanego and Nuria Yáñez-Bouza for their valuable feedback on an earlier version of this paper, to Tamara Bouso-Rivas for her helpful comments and suggestions (personal communication) and, last but not least, to the anonymous reviewers and the editors of Research in Corpus Linguistics for their time and consideration.
} 
impersonal verbs such as hunger, long, lust or thirst (Levin 1993: 194-195), which in PDE have developed prepositional objects (e.g. pregnant women lusting for pickles and ice cream. Lexico's Dictionary s.v. lust v.). Impersonal verbs of DESIRE have been found to alternate between impersonal and personal use in Old (500-1100) and/or Middle English (1100-1500; henceforth OE and ME, respectively), as illustrated in examples (1) and (2) below from the Middle English Dictionary (MED).

(1) $\mathrm{He}$ was for-hungred and lust to eten. he-SUBJ was starved and lusted to eat 'He was starved and desired to eat' (MED [c1390] Chart.Abbey HG [LdMisc 210] 353)

(2) Me lust no lenger lyue I-OBJ wish no longer live 'I do not wish to live any longer' (MED [a1400] Cursor [Trin-C R.3.8])

Example (1) illustrates a personal construction with a grammatical subject, he. Example (2), by contrast, illustrates an impersonal construction in which a grammatical subject is missing. In both examples, the first argument encodes the semantic role of EXPERIENCER, which represents the "animate being inwardly affected by an event or characterized by a state" (Traugott 1972: 34; see also Möhlig-Falke 2012: 31, fn. 12; Miura 2015: 6). According to McCawley (1976: 194), in impersonal constructions the EXPERIENCER may be said to denote a human being who is "unvolitionally involved in the state of affairs" expressed by the verb and who cannot, therefore, be conceptualised as the causer of the event or process.

The second argument encodes the semantic role of CAUSE, which in (1) is syntactically realised by a to-infinitive clause, to eten, and in (2) by a bare infinitive, no lenger lyue. Semantically, the CAUSE argument represents "something from which the experience emanates or by which the experience is effected" (Fischer and van der Leek 1983: 346).

In English, the impersonal construction is known to have started to disappear between 1400 and 1500 (van der Gaaf 1904: 142; Allen 1995: 441-442), but marginal impersonal instances are recorded until about two centuries later ${ }^{2}$ (see Visser 1963: §43; Möhlig-Falke 2012: 14-15). Thus, the EModE period, with which this study is

\footnotetext{
${ }^{2}$ As in the following example extracted from the Oxford English Dictionary (OED): a1556. Let hym come when hym lust. OED s.v. lust, v. $\dagger 2$.
} 
specifically concerned, is of interest from a historical point of view since impersonal verbs were in the process of readjusting their argument structure to the new possibilities of the grammatical system of English. A wide variety of factors have been claimed to affect the loss of impersonal patterns, giving rise to an extensive literature on the topic, which includes classical works in historical linguistics dating back to the early twentieth century (e.g. van der Gaaf 1904; Jespersen 1961: 208ff), followed by publications like McCawley (1976), Elmer (1981), Fischer and van der Leek (1983), Allen (1986, 1995) and more recently Trousdale (2008), Möhlig-Falke (2012) and Miura (2015), among many others.

After the loss of impersonal patterns, impersonal verbs developed a very idiosyncratic range of syntactic uses, some of which co-existed with impersonal patterns already in OE, as has been shown in previous work (e.g. Fischer and van der Leek 1983; Allen 1995: 286-287). It thus appears that

the loss of impersonal patterns proceeded over the respective verbs in a very gradual and seemingly unsystematic manner, in that individual verbs developed in different syntactic ways. (Möhlig-Falke 2012: 3-4)

The overall aim of the present study is to elucidate the path of development followed by formerly impersonal verbs of DESIRE, focusing initially on the verb lust as a case study. Future work will address the development of the other impersonal members of the class (hunger, long and thirst), so as to obtain a complete picture of this semantic class, which, as pointed out by Miura (2015: 244), has received little or no attention in the literature to date. The verb lust in particular has been selected as the object of study here because the meaning most commonly expressed by this verb until the mid-sixteenth century is 'to desire’ (e.g. a1425. No creature shal luste [i.e. desire] play [...]. OED s.v. lust, v. †3. a.; see also van der Gaaf 1904: 74-75). It is not until the late seventeenth century that the specialised sense 'to have a carnal desire' gains ground and survives up to the present day, though as a low-frequency usage (e.g. He really lusted after me in those days. Lexico's Dictionary s.v. lust verb).

As regards the specific objectives of this paper, they can be summarised as follows: 1) to determine the time when the verb lust exactly ceased to be recorded in impersonal constructions; 2) to provide a diachronic overview of the personal morphosyntactic patterns that came to replace impersonal constructions with this verb in the EModE period; 3) to describe the syntactic and semantic properties of the arguments of lust; 4) to 
reflect upon some of the factors which have been claimed to affect the loss of impersonal patterns in the history of English.

Section 2 offers an overview of the development of impersonal constructions in earlier English and the main hypotheses put forward in the literature about their disappearance. Section 3 is concerned with the syntactic and semantic properties of the class of verbs of DESIRE. Section 4 outlines the data sources and methodology employed in the study, while Section 5 looks at the origin and development of lust as well as the range of complementation patterns documented with this verb based on the entries of the OED, the MED and previous studies, looking at both impersonal and personal patterns. Section 6 presents and discusses the data on lust retrieved from the Early English Books Online Corpus 1.0 (1473-1700; henceforth EEBOCorp 1.0). Section 7 summarises the main findings and conclusions to be drawn from the study.

\section{THE DEVELOPMENT AND LOSS OF IMPERSONAL CONSTRUCTIONS}

Before we delve into the question of impersonal constructions, a few comments are in order regarding the use of the terms 'impersonal' and 'personal'. In my use of the term 'impersonal', I will follow Fischer and van der Leek (1983: 347) and Möhlig-Falke (2012: 6) in treating as impersonal those morphosyntactic patterns which lack a grammatical subject controlling verbal agreement. The term 'personal', conversely, will be applied to patterns which involve a grammatical subject controlling verbal agreement. For a discussion of the terminological and conceptual maze surrounding impersonal constructions, see Méndez Naya and López Couso (1997).

Various hypotheses have been put forward to try to explain the causes which may have led to the disappearance of impersonal constructions. Most notably, Jespersen's (1961) reanalysis hypothesis has dominated the discussion throughout the twentieth century and, in spite of the criticisms it has received, it has remained a major topic of discussion in the works of Fischer and van der Leek (1983) and Allen (1986, 1995), among many others. According to Jespersen (1961: 208-210), the EXPERIENCER argument in impersonal expressions underwent a process of reanalysis as a result of the syncretism of forms brought about by the simplification of the case system. Examples (3a)-(3d) below represent the hypothetical stages postulated by Jespersen (1961: 209) in order to account for the changes involved, which include, first, the richly inflected sentence in 
(3a), representative of $\mathrm{OE}$; second, the syncretism of case forms in the nominative and the dative represented in (3b), corresponding to early ME; and, third, the structural ambiguity in (3c), which eventually led to a confusion about which constituent functioned as subject and object of the clause. This structural ambiguity arose in OVS patterns with two NPs, like (3c), probably representative of late ME, and it eventually cancelled the possibility to place the oblique EXPERIENCER before the verb once word order became rigidified (Fischer and van der Leek 1983: 338-339). Thus, by the EModE period the EXPERIENCER was reanalysed as a subject, as represented in example (3d), with the morphologically marked pronoun he as the unambiguous subject of the clause.

(3a) pam cynge licodon peran the king-DAT/SG liked-PL pears-NOM/PL 'pears pleased the king'

(3b) the king liceden peares the king-SG liked-PL pears-PL 'pears pleased the king'

(3c) the king liked pears 'pears pleased the king/the king liked pears'

(3d) he liked pears

According to Jespersen (1961: 208), the "natural" outcome was for the EXPERIENCER to be reanalysed as subject, mainly due to "the greater interest taken in persons than in things, which caused the name of the person to be placed before the verb." Aside from this psychological explanation, Jespersen's account bears on the deep morphosyntactic transformations which the English language underwent during $\mathrm{OE}$ and $\mathrm{ME}$, namely the simplification of the case system, which has been dated in the twelfth and thirteenth centuries (Allen 1995: 213, 441) and the rigidification of word order, dated in the midfifteenth century (Fischer et al. 2000: 162; see also Möhlig-Falke 2012: 19, 216).

The reanalysis hypothesis, however, has been challenged on the basis of empirical data showing that impersonal patterns remained productive even after these changes were becoming complete (see e.g. Fischer and van der Leek 1983; Allen 1986, 1995). Allen (1986) in particular notes that Jespersen's claim cannot be upheld if we take into account that sentences such as (3a)-(3c) with two nominal NPs are actually highly infrequent in OE and ME for the impersonal verb like (see Allen 1986: 378). The reason for this is that it is not likely that the loss of case marking played a role if we bear in mind that case 
distinctions on pronouns remained clear in the majority of cases, so that formal ambiguity did not arise as a rule (see also McCawley 1976: 201-202; Fischer and van der Leek 1983: 339, 346ff). ${ }^{3}$

Even though the traditional account assumes that it was the EXPERIENCER argument rather than the CAUSE which was reanalysed as subject, several studies have pointed out that impersonal verbs in fact developed along various distinct syntactic paths (Fischer and van der Leek 1983: 365-366; Möhlig-Falke 2012: 217). For the purposes of this study, two of these paths are described in the paragraphs that follow (for a full account see e.g. Möhlig-Falke 2012: 217-218).

Path 1: The EXPERIENCER argument is interpreted as subject and the CAUSE argument, if expressed, is encoded as object. This path corresponds to so-called EXPERIENCER-subject constructions (Fischer and van der Leek 1983: 352-354) and it is the most common path of change of impersonal verbs (Möhlig-Falke 2012: 218). It is the path followed by hunger, like, need or thirst (e.g. She likes money. Fischer and van der Leek 1983: 363).

Path 2: The EXPERIENCER is interpreted as object and the CAUSE is encoded as the subject of the clause. This path corresponds to so-called CAUSE-subject constructions (Fischer and van der Leek 1983: 349-352; also EXPERIENCER-object constructions in Croft 1991: 219). This is the path followed by ail or please (e.g. Her decision pleased me. Fischer and van der Leek 1983: 363).

\section{SYNTACTIC AND SEMANTIC PROPERTIES OF VERBS OF DESIRE IN PDE}

Levin's (1993: 194-195) class of PDE verbs of DESIRE comprises (im)personal verbs such as crave, desire, need or yearn. According to Levin, the first argument of verbs of DESIRE, i.e. "the person that desires something," may be considered a type of EXPERIENCER, which is invariably encoded as the subject of the clause. The class may be further subdivided into want-verbs and long-verbs, depending on whether the second argument, i.e. "the thing desired" (Levin 1993: 194), is encoded by a direct object as in (4) —want-verbsor by a prepositional object as in (5) — long-verbs (examples from Levin 1993: 194-195).

\footnotetext{
${ }^{3}$ ME personal pronouns retain the subjective/objective case distinction in the majority of cases (Allen 1986: 378; e.g. ic/mē, wē/us, hê/him, etc.), except for the neuter (h)it/(h)it. Notice, in addition, that case distinctions were more pervasive in $\mathrm{ME}$ than in $\mathrm{PDE}$, since the ME second-person plural form ge still maintained the distinction between ge 'ye' (subjective) and eow 'you' (objective) (Allen 1986: 378, fn. 2).
} 
The particular case of lust is representative of the long-class, as it has developed prepositional uses in PDE (e.g. pregnant women lusting for pickles and ice cream; see Section 1).

(4) Dorothy needs new shoes.

(5) Dana longs for a sunny day.

Verbs of DESIRE are two-place predicates with the semantic frame <EXPERIENCER, CAUSE $>$. In order to characterise the semantic properties of the participants of verbs of DESIRE, the present study makes use of Dowty's (1991: 576) concept of Proto-role, which conceives semantic roles as prototypical categories formed by clusters of semantic features. Dowty (1991: 551) also introduces the 'Argument Selection Principle', which rests on the assumption that the argument that shows the greatest number of so-called Proto-agent properties will be encoded as subject, whereas the argument with the greatest number of Proto-patient properties will be encoded as direct object. The semantic clusters of features that characterise the Proto-agent and Proto-patient roles are displayed in Table $1 .^{4}$

\begin{tabular}{lll}
\hline \hline & Proto-agent & Proto-patient \\
\hline 1. & Volitional involvement in the event or state & Undergoes change of state \\
2. & Sentience (and/or perception) & Incremental THEME \\
3. & $\begin{array}{l}\text { Causing an event or change of state in } \\
\text { another participant }\end{array}$ & Causally affected by another participant \\
4. $\begin{array}{l}\text { Movement (relative to the position of } \\
\text { another participant) }\end{array}$ & $\begin{array}{l}\text { Stationary (relative to movement of another } \\
\text { participant) } \\
\text { 5. } \begin{array}{l}\text { Exists independently of the event named by } \\
\text { the verb }\end{array}\end{array}$ & $\begin{array}{l}\text { Does not exist independently of the event, or not } \\
\text { at all }\end{array}$ \\
\hline \hline
\end{tabular}

Table 1: Semantic features of the Proto-agent and Proto-patient roles (adapted from Dowty 1991: 572)

In the framework of Dowty (1991), it becomes apparent that the CAUSE argument of verbs of DESIRE lacks the majority of Proto-patient properties. Thus, the CAUSE does not undergo a change of state (Property 1), it is not an incremental THEME (Property 2), it is not causally affected by another participant (Property 3), it does not lack movement relative to the position of another participant (Property 4) and it does have independent existence from the event named by the verb (Property 5).

\footnotetext{
${ }^{4}$ An incremental THEME is "an NP that can determine the aspect of the sentence, since the parts of the event correspond to parts of the NP referent that are affected by the action; the event is 'complete' only if all parts of the NP referent are affected (or effected)" (Dowty 1991: 588; cf. Hopper and Thompson's (1980: 252253) 'affectedness of object'). An example of incremental THEME would be, for instance, the NP in the sentence mow the lawn, where the telic aspect of the event of mowing can be deduced from "whether the grass on the lawn is all tall, partly short, or all short" (Dowty 1991: 267).
} 


\section{DATA SOURCES AND METHODOLOGY}

The present study is based on data drawn from EEBOCorp 1.0, an offline version of Early English Books Online (EEBO), which comprises works printed between 1473 and 1700 in subject areas such as English literature, linguistics, theology or fine arts. EEBOCorp 1.0 largely reproduces the database provided by EEBO, and thus includes all texts in EEBO Phase I with no genre, wordcount balance or codification for text type or subject domain. EEBOCorp 1.0 excludes non-English as well as posthumous texts, and it also filters out translations from works by long-deceased authors, even if these are not posthumous from the point of view of the translator. ${ }^{5}$

The size of the corpus is extremely large (525 million words) and it is perhaps not always ideal for research on frequent items, given the high number of hits retrieved whenever homonyms are involved, as happens in the present case with the verb lust versus the noun lust. In order to work with a manageable number of hits, a random selection of texts has been made totalling c. 20 million words, and including only texts written in prose. As laid out in Table 2, the corpus is structured into four sub-corpora of comparable size, across four 50-year subperiods.

\begin{tabular}{ccc}
\hline \hline Subperiod & $\begin{array}{c}\text { No. of } \\
\text { texts }\end{array}$ & $\begin{array}{c}\text { No. of } \\
\text { words }\end{array}$ \\
\hline S1 (1500-1549) & 200 & $4,969,243$ \\
S2 (1550-1599) & 226 & $4,997,385$ \\
S3 (1600-1649) & 230 & $5,003,071$ \\
S4 (1650-1700) & 235 & $4,929,578$ \\
Total & 891 & $19,899,277$ \\
\hline \hline
\end{tabular}

Table 2: Number of texts and wordcount per 50-year subperiod

The dataset of examples with lust retrieved from these 891 texts consists of 273 occurrences. The selected software tool for data search is the concordancer AntConc (Anthony 2019). In order to identify the array of spelling variants for this verb, I first gathered the list of possible spellings provided in the OED and then checked them against the corpus word list from EEBOCorp 1.0 generated with AntConc. The ensuing syntactic analysis was carried out by annotating the data for factors concerning the types of clause where lust occurs (e.g. 'type of complementation pattern', 'main/subordinate clause', 'type of subordinate clause') and the formal realisation of arguments (e.g. 'formal realisation of the EXPERIENCER/CAUSE', 'preposition', 'personal pronoun'). For its part,

\footnotetext{
${ }^{5}$ I am grateful to Peter Petré for giving me access to this corpus.
} 
the semantic analysis considered the Proto-role properties postulated by Dowty (1991) and outlined in Section 3 above. The data were annotated for factors related mainly to the features of volition (Property 1, 'volitional/unvolitional'), the feature of sentience (Property 2, 'sentient/non-sentient'), the feature of causation (Property 3, 'causation/no causation'), the feature of movement relative to the position of another participant (Property 4, 'movement/no movement') and the feature of existence independently of the event (Property 5, 'existence/no existence').

\section{ORIGIN AND COMPLEMENTATION PATTERNS OF LUST}

In this section, I look at the origin and development of lust, from ME lusten. The MED first documents lust in c1175 (?OE), although the original text presumably dates back to the OE period (MED s.v. lusten v. 1. [d]). The history of lust prior to ME is uncertain. According to the OED, lust derives from the noun lust 'pleasure, delight', a word inherited from Germanic, and it is first attested in the early thirteenth century (OED, s.v. lust, v. $\dagger 1$ a.). The MED, however, states that lust originates from both the ME noun lust (OE lust) and the OE verb lystan 'to desire', the most frequent verb in OE impersonal patterns with genitive or prepositional complements (i.e. Allen's 'Type N', 1995: 70-71; see also Möhlig-Falke 2012: 115). The present study follows Miura (2015: 62) in treating lustand list-forms as separate lexical items on the grounds that the OED and the MED give them separate entries.

Judging from the OED, the MED and previous studies, the impersonal use of lust is first documented in the twelfth century in texts which were (presumably) composed in the OE period (see e.g. MED s.v. lusten v. 1. [a] and [d]), and is last attested in the midsixteenth century (see OED s.v. lust, v. †2.). ${ }^{6}$ In impersonal use, lust is found with a pronominal EXPERIENCER in the objective case in combination with three different types of complements representing the semantic role of CAUSE: 1) CAUSE as clausal complement (see example (2) above); 2) CAUSE as prepositional complement (e.g. a1393. Hem lusteth of no ladi chiere 'They do not desire the countenance of a lady'); ${ }^{7}$ and 3) CAUSE as zero complement (e.g. c1475 [1392]. By cause of heete him lustip myche 'Because of the heat he feels a great longing').

\footnotetext{
${ }^{6}$ Unless otherwise stated, examples in this section are taken from the OED and the MED entries.

${ }^{7}$ I thank Ayumi Miura for her helpful opinion on the interpretation of this example.
} 
A variant of impersonal patterns with clausal complements can be found in subordinate clauses where a proposition is omitted but retrievable from the preceding context; this is signalled by the empty brackets in the following examples: as him lusteth [ ], when him lusteth [ ], to be compared with analogous structures taking an explicit clausal complement (e.g. c1390 [?c1350]. Whon pe lust speke with me). Similar constructions are observed since $\mathrm{OE}$ times, for instance with the $\mathrm{OE}$ verb lystan (e.g. eal paet hine lystep 'all that he likes', from Elmer 1981: 117 [my translation]) or lician (e.g. OE ... pe estað heom silfum swa heom betst licað ... 'who himself lives in luxury, as pleases him best', from Möhlig-Falke 2012: 144, 205). Examples like these will be termed impersonal NO PROPs (short for 'unexpressed proposition'), after Allen (1995: 86, 257258, 275-277), and they include subordinate clauses introduced by as or what, when and variants (e.g. whatsoever or whenever) ${ }^{8}$

Judging from the OED, the MED and previous studies, the personal use of lust first emerged in the fourteenth century (see e.g. MED s.v. lusten v. 2. [a]), which is about two centuries after impersonal use is first documented in the twelfth century. This suggests that in its initial stages lust must have been restricted to impersonal use only. In addition, this also implies that personal constructions (with EXPERIENCER subjects) emerge at a time when the loss of case distinctions was at an advanced stage, whereas the fixation of word order was at an intermediate stage (see Section 2). It is also noteworthy that the personal use of lust is always found in EXPERIENCER-subject constructions, but never in CAUSEsubject (see also Miura 2015: 181, especially her Table 5.33).

In personal use, three different types of complementation patterns can be found, depending on the expression of the CAUSE argument, namely: 1) patterns with clausal complements (e.g. 1586. Insomuche as hee that neuer lusted to helpe others, was not nowe able to helpe himselfe); 2) patterns with NP complements (e.g. 1653. The Spirit and the flesh are contraries, and they lust contrary things); and 3) prepositional patterns (e.g. 1563. If we be an hungred, we lust for bread).

As with impersonal constructions with NO PROPs, a variant of personal patterns with clausal complements can be found in subordinate clauses where a proposition is

\footnotetext{
${ }^{8}$ NO PROP constructions are considered to omit a clausal rather than an NP complement because: 1) a clausal complement can be inserted without affecting the grammaticality of the clause (cf. [1404]. Alle his Justices and his Sergeantz and othir suche as hym lust name); and 2) evidence has been found of analogous structures taking an explicit clausal complement, but not an NP complement (? as him lusteth NP; ?when him lusteth NP).
} 
understood (e.g. 1526. They.. have done vnto him whatsoever they lusted [ ]). These will be termed as personal NO PROPs, in parallel to Allen's (1995) impersonal NO PROPs outlined above. In like manner, the personal NO PROP corresponds to subordinate clauses introduced by as or what, when and variants. ${ }^{9}$

\section{LUST IN THE EMODE PERIOD}

Table 3 displays the overall frequency of lust in EEBOCorp 1.0 distributed by 50-year subperiod and subject domain. ${ }^{10}$ Note that the category 'General Prose' includes text types such as manuals of style or biographies which are not clearly classifiable into any of the other domains identified.

\begin{tabular}{cccccc}
\hline \hline $\begin{array}{c}\text { Subject } \\
\text { domain }\end{array}$ & $\begin{array}{c}\text { S1 } \\
(\mathbf{1 5 0 0}-\mathbf{1 5 4 9})\end{array}$ & $\begin{array}{c}\text { S2 } \\
(\mathbf{1 5 5 0}-\mathbf{1 5 9 9})\end{array}$ & $\begin{array}{c}\text { S3 } \\
(\mathbf{1 6 0 0}-\mathbf{1 6 4 9})\end{array}$ & $\begin{array}{c}\text { S4 } \\
(\mathbf{1 6 5 0}-\mathbf{1 7 0 0})\end{array}$ & Total \\
\hline Religion & $128(90.1)$ & $46(78)$ & $30(81.1)$ & $32(91.4)$ & $236(86.4)$ \\
General Prose & $8(5.6)$ & $10(16.9)$ & $4(10.8)$ & $1(2.9)$ & $23(8.4)$ \\
History & $6(4.2)$ & -- & $1(2.7)$ & $2(5.7)$ & $9(3.3)$ \\
Philosophy & -- & $2(3.4)$ & $1(2.7)$ & -- & $3(1.1)$ \\
Law & -- & -- & $1(2.7)$ & -- & $1(0.4)$ \\
Politics & -- & $1(1.7)$ & -- & -- & $1(0.4)$ \\
Biology & -- & -- & -- & -- & -- \\
Literature & -- & -- & -- & -- & -- \\
Medicine & -- & -- & -- & -- & -- \\
Total & $142(100)$ & $59(100)$ & $37(100)$ & $35(100)$ & $273(100)$ \\
\hline \hline
\end{tabular}

Table 3: Frequency distribution of EModE lust by 50 -year subperiod and subject domain (raw figures and percentages)

As said earlier, the search for this verb yielded a total of 273 tokens. It can be observed in the table that the overall frequency of lust notably decreases in the course of EModE, a diachronic picture that reflects its status as a low-frequency verb in PDE (see OED s.v. lust, v. Frequency [in current use]). It can also be seen that lust is predominantly found in religious and biblical contexts $(86.4 \%)$, and this is consistent across the four subperiods. ${ }^{11}$ In contrast, the frequency in the other subject domains is anecdotal overall, with some domains showing no attestations, such as Biology, Literature and Medicine, whereas some other domains show subperiods with no data, like Philosophy, Law and Politics.

\footnotetext{
${ }^{9}$ Subordinate clauses introduced by as or what, when and variants are all equally subsumed under NO PROPs because they have in common with the latter that a proposition can be added without affecting the grammaticality of the clause (e.g. as they lusted [to do]; whatsoever they lusted [to do]).

${ }^{10}$ Since EEBOCorp 1.0 does not provide its data coded for text type or subject domain, the classificatory labels adopted here have been devised specifically for the purposes of this research, based on the information gleaned from the text files themselves.

${ }^{11}$ Note that religious discourse is generally characterised by the use of archaic language, which is highly dependent on Latin (see e.g. Görlach 1993: 164-165).
} 
In the following sections, the impersonal and personal uses found in the corpus are discussed. Section 6.1 focuses on impersonal patterns, while Section 6.2 looks at personal ones; but, before we delve into the discussion, a note needs to be made regarding their overall distribution. In the data from the EModE period, the impersonal use of lust is documented in just $6.2 \%$ of total occurrences (17 tokens). Impersonal patterns are therefore the least frequent use as against personal constructions, with a ratio of 1 impersonal to 15 personal instances, and, crucially, all the impersonal instances are attested in the earliest period S1 (1500-1549). It is noteworthy that, even though personal constructions start to be recorded only from the fourteenth century (see Section 5), in the EModE period personal patterns already represent $93.8 \%$ of cases (256 tokens), which may be taken as an indication that the shift from impersonal to personal use must have taken place during the late ME period.

\subsection{Impersonal patterns in EModE}

The data in Table 4 show that, with regard to the formal realisation of the EXPERIENCER argument, unambiguous impersonal patterns have been attested only with pronominal EXPERIENCERS, namely me (example (9)), thee/the (example (7)), him/hym (example (6)) and them (example (8)). ${ }^{12}$ With respect to the formal realisation of the CAUSE, in the EModE data it is realised by a to-infinitive clause (example (6)) or a NO PROP (examples (7)-(9)); no examples have been attested with either zero complements or prepositional phrases.

\footnotetext{
${ }^{12}$ Instances with nominal EXPERIENCERS have been counted as personal for two main reasons: 1) nouns are uninflected for case in the data here examined; and 2) the rigidification of word order was well advanced by the EModE period (see Section 2). It thus seems reasonable to assume that uninflected nominal EXPERIENCERS in preverbal position functioned as grammatical subjects in the period of study. As for the second-person plural pronouns yelyou, even though these retain case distinctions for the most part of the sixteenth century (Barber 1997: 149), no instances have been found where the originally objective you form represents the EXPERIENCER of an impersonal pattern (i.e. ?you lusteth).
} 


\begin{tabular}{cccccccc}
\hline \hline & $\begin{array}{c}\text { Main } \\
\text { clause }\end{array}$ & \multicolumn{5}{c}{ Subordinate clause } \\
\hline CAUSE & & Noun & EXPERIENCER \\
& & & $m e$ & thee/the & $\begin{array}{c}\text { Pronoun } \\
\text { him/hym }\end{array}$ & them & Total \\
& & -- & -- & -- & 1 & -- & 1 \\
TO-INF & -- & -- & 1 & 3 & 11 & 1 & 16 \\
NO & -- & -- & 1 & 3 & 12 & 1 & 17 \\
PROP & -- & - &
\end{tabular}

Table 4: Distribution of morphosyntactic properties of impersonal patterns with EModE lust (raw figures)

(6) 1531. so that this full power shulde be able to do any dede that is possible to be done, or any thynge that hym lustethe to do. (D00000998431390000.txt)

(7) 1536. and that thou mayst be fre to vse thy wordes as the lusteth. (D00000998400370000.txt)

(8) 1539. What so euer them lusteth, that proudly and stubburnly they dare do. (D00000998548110000.txt)

(9) 1549. Is it not lawful for me to do as me lusteth with mine owne goodes? (D00000999002540000.txt)

Impersonal patterns appear predominantly in NO PROP constructions such as those exemplified in (7)-(9) above, with the latest occurrence being recorded in 1549, and illustrated in example (9); there is only one exception to NO PROPs, corresponding to the to-infinitive complement in the earliest example (6). The impersonal NO PROP construction seems to show a significant degree of fossilisation, for it is attested with the third-person masculine singular pronoun him/hym in $70.6 \%$ of cases; further, it is introduced predominantly by as or what, when and variants (respectively 5 and 11 tokens). Overall, the high incidence of these fossilised structures suggests that the degree of productivity of the impersonal construction was limited already in the early sixteenth century. It may be that these NO PROPs constitute a remnant of an impersonal pattern which was previously at work, but which in EModE remains only as a fossilised expression preceding the total obsolescence of impersonal patterns with this verb.

\subsection{Personal patterns in EModE}

In the following paragraphs, the discussion focuses on the historical development of the personal patterns documented in EEBOCorp 1.0 (1500-1700), which vary in the number and nature of the arguments expressed. The complementation patterns attested in EModE 
include: 1) patterns with clausal complements (example (10)); 2) patterns with NP complements (example (11)); patterns with zero complements (example (12)); and 4) prepositional patterns (example (13)).

(10) 1529. Likewise (saide he) muste thou also punisshe and chastise thy silfe yf so thou luste to serve god. (D00000998455470000.txt)

(11) 1538. he shoulde luste those thynges that lawes allow. (D00000998408250000.txt)

(12) 1548. Thou shalt not desire or lust. (D00000998449220000.txt)

(13) 1628. Not to look upon the wine when it giveth his colour in the glasse; his meaning is, we should not lust vehemently after it.

(D00000222874350000.txt)

Table 5 shows the raw frequencies for each of the documented personal patterns, with percentages in brackets; in parallel, Figure 1 provides the relative frequencies distributed across the four 50-year subperiods under analysis. ${ }^{13}$

\begin{tabular}{cccccc}
\hline \hline $\begin{array}{c}\text { Complementation } \\
\text { pattern }\end{array}$ & $\begin{array}{c}\text { S1 } \\
(\mathbf{1 5 0 0 - 1 5 4 9 )}\end{array}$ & $\begin{array}{c}\text { S2 } \\
(\mathbf{1 5 5 0}-\mathbf{1 5 9 9})\end{array}$ & $\begin{array}{c}\text { S3 } \\
(\mathbf{1 6 0 0}-\mathbf{1 6 4 9})\end{array}$ & $\begin{array}{c}\text { S4 } \\
(\mathbf{1 6 5 0}-\mathbf{1 7 0 0})\end{array}$ & Total \\
\hline Clausal & $59(47.2)$ & $22(37.3)$ & $6(16.2)$ & $5(14.3)$ & $92(35.9)$ \\
Zero & $32(25.6)$ & $21(35.6)$ & $16(43.2)$ & $22(62.9)$ & $91(35.5)$ \\
Prepositional & $29(23.2)$ & $15(25.4)$ & $14(37.8)$ & $7(20)$ & $65(25.4)$ \\
NP & $5(4)$ & -- & - & $1(2.9)$ & $6(2.3)$ \\
Other & -- & $1(1.7)$ & $1(2.7)$ & -- & $2(0.8)$ \\
Total & $125(100)$ & $59(100)$ & $37(100)$ & $35(100)$ & $256(100)$ \\
\hline \hline
\end{tabular}

Table 5: Frequency of personal patterns with EModE lust by 50-year subperiod (raw figures and percentages)

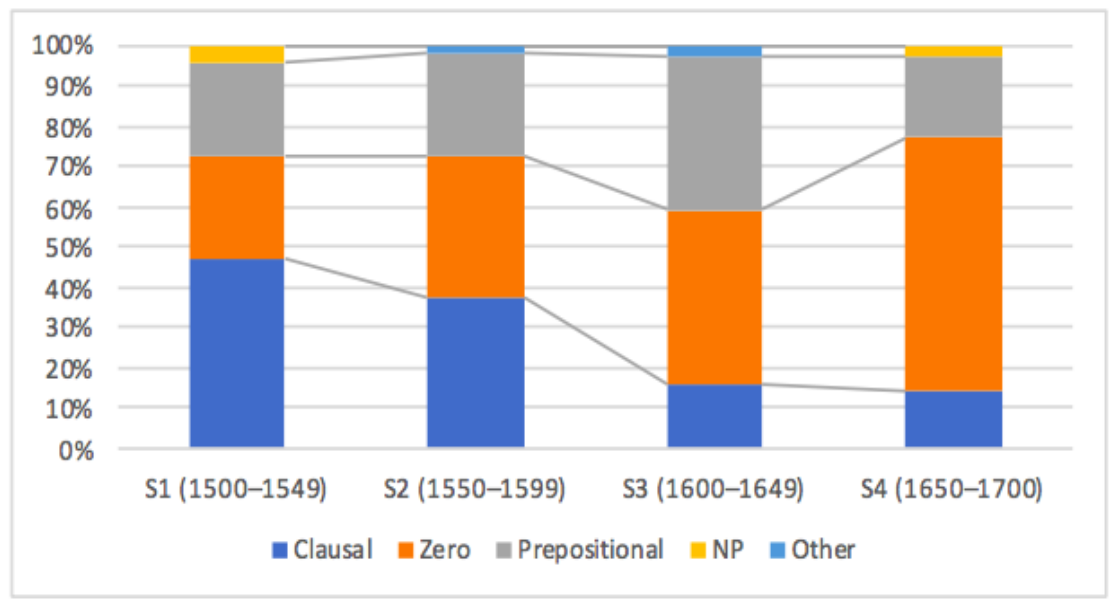

Figure 1: Diachronic distribution of personal patterns with EModE lust (relative frequencies)

\footnotetext{
${ }^{13}$ The category 'Other' includes instances of lust which have not been identified due to difficulties of interpretation, usually because they lack the morphosyntactic information needed for an unambiguous categorisation (e.g. 1535. thou shall not lust or concupisce [Illegible_Word] desire).
} 
The overall relative frequencies suggest a similar distribution in clausal and zero complements, both at approximately 36\%. Prepositional patterns show a lower frequency at $25.4 \%$, while patterns with NP complements constitute the smallest proportion of occurrences at $2.3 \%$. The diachronic evolution across subperiods reveals crucial differences with regard to the frequency of complementation patterns. Zero complements show a steady increase, rising from $25.6 \%$ of the instances in S1 to $62.9 \%$ in S4. In turn, clausal complements show a parallel decrease over time, gradually from the earliest supberiod - when they clearly dominated in frequency at $47.2 \%$ - to the final subperiod. At the turn of the sixteenth century, clausal complements undergo a marked decline from $37.3 \%$ - still competing in frequency with zero complements - to $16.2 \%$ in the early seventeenth century -i.e. less than half the frequency of the pattern with zero complements. For their part, patterns with prepositional complements remain constant except for the small increase from $25.4 \%$ in S2 to $37.8 \%$ in S3, standing below zero complements and clausal complements in S1 and S2, but only below zero complements in S3 and S4. As far as patterns with NP complements are concerned, these are modestly represented in S1 (4\%), unattested in S2 and S3, and occur again anecdotally in S4 (one token, 2.9\%). Overall, we may conclude that the data unveil a contrast between the sixteenth (i.e. S1 and S2) and the seventeenth centuries (i.e. S3 and S4), especially in connection with the diachronic development of clausal and prepositional complements, which show the sharpest shifts in frequency between S2 (1550-1599), S3 (1600-1649) and S4 (1650-1700).

Table 6 provides the frequencies for the formal realisation of the EXPERIENCER argument, only concerning finite clauses where a grammatical subject is overtly present. The realisation of the CAUSE argument will be dealt with in Sections 6.2.1 to 6.2.4.

\begin{tabular}{cccc}
\hline \hline Complementation pattern & Noun & Pronoun & Total \\
\hline Clausal & $7(7.9)$ & $82(92.1)$ & $89(100)$ \\
Zero & $43(55.8)$ & $34(44.2)$ & $77(100)$ \\
Prepositional & $8(20)$ & $32(80)$ & $40(100)$ \\
NP & -- & $3(100)$ & $3(100)$ \\
Total & $58(27.8)$ & $151(72.2)$ & $209(100)$ \\
\hline \hline
\end{tabular}

Table 6: Formal realisation of the EXPERIENCER argument in personal patterns with EModE lust (raw figures and percentages)

The data show that pronominal EXPERIENCERS are generally favoured, with $72.2 \%$ of total instances; out of 151 tokens, $128(84.8 \%)$ represent personal pronouns distinct from relative or interrogative forms. The attested personal pronouns are the following, in order 
of frequency: they (34 tokens, 26.6\%), ${ }^{14}$ he (20 tokens, 15.6\%), yelyou (20 tokens, $15.6 \%)$, thou (18 tokens, $14.1 \%)$, we (16 tokens, 12.5\%), it (15 tokens, 11.7\%), I (4 tokens, 3.1\%) and she (one token, $0.8 \%$ ). The attested personal pronouns are always declinable (e.g. they/them, we/us, etc.). The second-person plural forms ye/you are counted as declinable because they are not used interchangeably for the most part of the sixteenth century (Barber 1997: 149). As for the neuter pronoun it, it is also counted as declinable because it has the old dative form him "as an alternative to accusative it all through the sixteenth century" (Barber 1997: 150).

Patterns with clausal and prepositional complements clearly prefer pronominal EXPERIENCERS, which respectively represent $92.1 \%$ and $80 \%$ of total instances, as is the case also with NP complements, which occur exclusively with pronominal EXPERIENCERS. On the other hand, zero complements are the only realisation that prefers nominal EXPERIENCERS, slightly over pronominal forms at $55.8 \%$. This may well be due to the high incidence of the fossilised expression the flesh lusts against/contrary to the spirit and its variants, to be dealt with in Section 6.2.2. Figure 2 below shows the diachronic distribution of nominal and pronominal EXPERIENCERS. Notice that, even though pronominal EXPERIENCERS are by far the most common realisation overall, from a diachronic perspective nominal EXPERIENCERS undergo a considerable increase throughout the period.

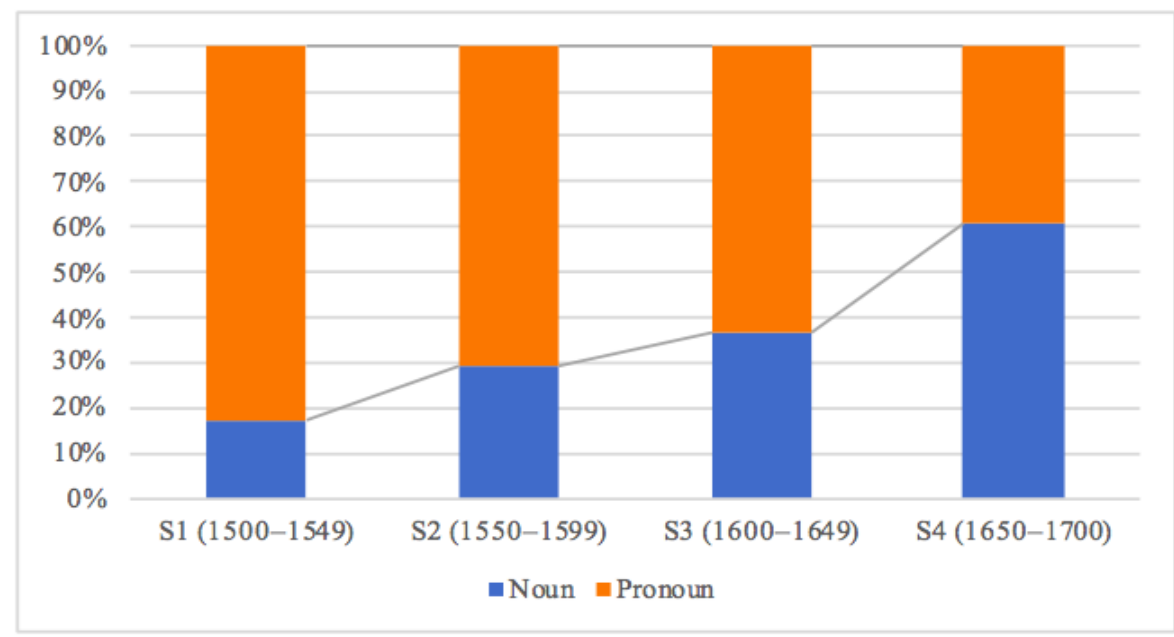

Figure 2: Diachronic distribution of nominal and pronominal EXPERIENCERS in personal patterns with EModE lust (relative frequencies)

\footnotetext{
${ }^{14}$ Note that the percentage of personal pronouns is calculated relative to the total number of personal pronouns, i.e. 128 tokens.
} 


\subsubsection{Patterns with clausal complements}

In patterns with clausal complements, a (pro)nominal argument in the subjective case expresses the semantic role of EXPERIENCER and a clausal complement expresses the semantic role of CAUSE. According to the MED, personal patterns with clausal complements are first attested with lust in the fourteenth century (s.v. lusten v. 2. [a]). Table 7 provides the distribution for each of the realisations attested.

\begin{tabular}{cccccc}
\hline \hline \multirow{2}{*}{ CAUSE } & S1 & S2 & S3 & S4 & \multirow{2}{*}{ Total } \\
& $(\mathbf{1 5 0 0}-\mathbf{1 5 4 9 )}$ & $(\mathbf{1 5 5 0}-\mathbf{1 5 9 9 )}$ & $\mathbf{( 1 6 0 0 - 1 6 4 9 )}$ & $\mathbf{( 1 6 5 0 - 1 7 0 0 )}$ & \\
\hline NO PROP & $40(67.8)$ & $19(86.4)$ & $2(33.3)$ & $1(20)$ & $62(67.4)$ \\
TO-INF & $19(32.2)$ & $3(13.6)$ & $4(66.7)$ & $4(80)$ & $30(32.6)$ \\
TOTAL & $59(100)$ & $22(100)$ & $6(100)$ & $5(100)$ & $92(100)$ \\
\hline \hline
\end{tabular}

Table 7: Formal realisation of clausal complements in personal patterns with EModE lust (raw figures and percentages)

(14) 1528. there is no strength in their membres to doo that which their herte lusteth to do. (D00000998406010000.txt)

(15) 1528. What reason is it that myne enimy shulde put me in prison at his pleasure and there diet me and handyll me as he lusteth. (D00000998406010000.txt)

(16) 1539. Honour is offered vs, and suche honour vndoubtedly as neuer came to our nation, if we lust to take it. (D00000998400250000.txt)

The category of NO PROPs yields the highest number of instances (62 tokens, 67.4\%; example (15)), followed by to-infinitive complements (30 tokens, $32.61 \%$; examples (14) and (16)). These two variants show differences with regard to the realisation of the EXPERIENCER argument; thus, NO PROPs are found with nominal EXPERIENCERS in just one out of 62 cases, whereas the variant with a to-infinitive occurs with nominal EXPERIENCERS in 6 out of 30 cases; hence, the construction with a to-infinitive accounts for 6 out of 7 total nominal EXPERIENCERS (cf. Table 6, Section 6.2). Further, these two formal realisations show differences with regard to distribution by clause type: whereas NO PROPs are by default confined to subordinate clauses (62 tokens), to-infinitive complements may occasionally occur in main clauses (3 tokens). From a diachronic perspective, it is also noteworthy that the variant with NO PROPs predominates in the two subperiods of the sixteenth century, whereas the variant with to-infinitive does so in the two subperiods of the seventeenth century. That is, NO PROPs undergo an increase in S2 at $86.4 \%$, but they decrease dramatically in S3 at 33.3\% and in S4 at 20\% (see Table 7 above). In parallel, to-infinitives decrease abruptly after S1 to $13.6 \%$, but they rise up again to $66.7 \%$ in S3 and $80 \%$ in S4, though only with 4 tokens each. It can thus be 
observed that a change takes place in the clausal complementation of lust since, as clausal complements become less frequent overall (see Table 5 and Figure 1), they also tend to disfavour an implicit realisation of the CAUSE.

Personal NO PROPs most likely represent a development of the impersonal NO PROPs discussed in Section 6.1. Personal NO PROPs share with impersonal NO PROPs that they both show a clear preference for pronominal subjects. A closer analysis of examples has revealed that in (17) below the personal NO PROP what they lust co-occurs with the impersonal what him lusteth. Notice that the personal variant takes the thirdperson plural pronoun they, whereas the impersonal variant takes the third-person masculine singular pronoun him, as it often happens with the impersonal NO PROPs found in the corpus. In order to assess the co-occurrence properties of personal and impersonal NO PROPs, I have examined the 14 texts where impersonal patterns have been found. It turns out that where the impersonal NO PROP takes the third-person pronoun him/hym, the personal variant with he tends to be absent. In fact, impersonal NO PROPs with him/hym co-occur with personal NO PROPs with he in only one out of the 14 texts examined. In this particular text, I found one token of impersonal NO PROP, corresponding to example (17) below, alongside 4 tokens of personal NO PROP with he (e.g. 1528. and with him is lawfull what he lusteth). This indicates that the impersonal NO PROP with him/hym is retained in this context instead of the personal counterpart, which might be seen as an effect of the high degree of fossilisation and the low degree of subject variation of the impersonal patterns found in the corpus.

(17) 1528. Then love I my most enimie Now when we saye every man hath his fre will to doo what him lusteth I saye verely that men doo what they lust. (D00000998406010000)

From a semantic perspective, it should be remembered that in impersonal constructions the EXPERIENCER was said to denote a human being who is "unvolitionally involved in the state of affairs" (McCawley 1976: 194). Surprisingly, however, this is not the function observed in example (17) above, where the EXPERIENCER (every man) is explicitly said to have his fre will to do what he deliberately lusteth [i.e. chooses] to do. A similar function has been identified for personal NO PROPs in Allen (1995: 339), who points out that the personal NO PROP with please entails that "the Experiencer [...] is in control of the action of the main clause [...]." Hence, in a NO PROP construction like I'll stay as late as I please, the subject $I$ is given the freedom to stay for as long as he or she wishes to stay, emphasising the volitional nature of the EXPERIENCER, similarly to the impersonal 
construction in (17). On the face of it, it is unexpected that the impersonal and the personal variant of NO PROPs may equally attribute freedom of choice to the EXPERIENCER, when impersonal constructions have been said to denote a human being who is unintentionally involved in the event. It also seems paradoxical that impersonal constructions survive the longest in a construction type which, in the personal counterpart, contradicts their original OE function. A possible motivation for this is that the original function of impersonal constructions may have become vague in the EModE period. Going along with this, Miura (2015: 29) also observes for the ME period that "functional distinctions between the two [i.e. impersonal and personal] constructions were not always alive in late Middle English at least."

\subsubsection{Patterns with zero complements}

In patterns with zero complements, a noun or pronoun in the subjective case expresses the semantic role of EXPERIENCER, which is the only verbal argument. Since lust is a twoplace predicate (see Section 3), it would therefore be expected to occur predominantly in clauses with two explicit arguments (cf. the OED and the MED entries). In the corpus, this is the case in the two subperiods of the sixteenth century, when clausal patterns are the preferred option; however, from the turn of the century onwards, zero complements rise in frequency and become prevalent (see Table 5 and Figure 1). Examples (18)-(20) illustrate zero complements with lust.

(18) 1528. The law whe it co maundeth that thou shalt not lust. (D00000998406070000.txt)

(19) 1528. the whole nature of ma is damnyd in that $y^{\wedge}$ hert lusteth co trary to $y^{\wedge}$ will of God. (D00000998406070000.txt)

(20) 1535. For the fleshe lusteth continualy agenst the sprite. (D00000998394710000.txt)

The CAUSE is left unexpressed in all of (18)-(20) above, although it may be understood as referring to the notion of sin from the religious context in which the verb is found, especially in example (18): 'thou shalt not lust [to sin/after sin]'. In (18), there are no adverbial elements in the clause and the verb denotes a '[s]ensuous appetite or desire, considered as sinful or leading to sin' (OED s.v. lust, n. 3.). In example (19), by contrast, an adjunct PP is introduced headed by the complex preposition contrary to. Likewise, a PP adjunct is present in (20), but in this last case it forms part of the fossilised expression 
the flesh lusts against/contrary to the spirit, which expresses the meaning 'the body has carnal desires contrary to the spirit'. Alongside the variant the spirit lusts against/contrary to the flesh, this expression accounts for $26.4 \%$ of the total of zero complements (24 tokens).

PP adjuncts headed by against/contrary to are not documented in the OED or the MED. Similar uses, however, are documented with the near-synonymous verb covet (e.g. c1386. The flessh coueiteth agayn the spirit, defined as 'to lust' in the OED, s.v. covet, v. $\uparrow 4$. a.), with which lust appears in coordination on two occasions in the EModE data, as in (21) below.

(21) 1538. where as the flesh coueteth and lusteth agaynst the spiryte. (D00000239970610000.txt)

The high overall frequency of patterns with zero complements is partly due to the fact that they are notably represented by this formulaic expression, which is typical of the religious domain where lust is most common (see Table 3, especially the 'Total' for Religion). We can infer then that patterns with zero complements might not be highly productive, which is further supported if we take into account that the range of lexical nouns in subject function is considerably narrow. There are 7 different types of noun which add up to a total of 43 tokens, 30 of which correspond to flesh and 8 to spirit; the type/token ratio, which is 0.16, is therefore substantially low (cf. Bybee 2010: 94, 195). It thus appears that, although zero complements are found with high frequency, the likelihood that the pattern was used at the time to create novel utterances is limited.

\subsubsection{Prepositional patterns}

In prepositional patterns, a nominal or pronominal argument in the subjective case expresses the semantic role of EXPERIENCER, while a prepositional complement expresses the semantic role of CAUSE. According to the OED, this pattern is found with lust from the sixteenth century onwards, but in the EModE data prepositional patterns already represent $23.2 \%$ of uses in S1 (see Table 5 and Figure 1).

In EModE, the CAUSE argument is realised by a noun in $68.2 \%$ of cases (45 tokens) and by a pronoun in $31.8 \%$ of cases ( 21 tokens). The prepositional phrase expressing the CAUSE has been found to be headed by the prepositions after (59 tokens; example (22)), for (5 tokens; example (23)) and unto (one token; example (24)). Figure 3 shows their 
relative frequency across subperiods. The preposition after is the most frequent collocation, a trend that remains stable throughout the EModE period. The preposition for is attested 3 times in S1, twice in S2 and then disappears. Unto is attested only once in S4.

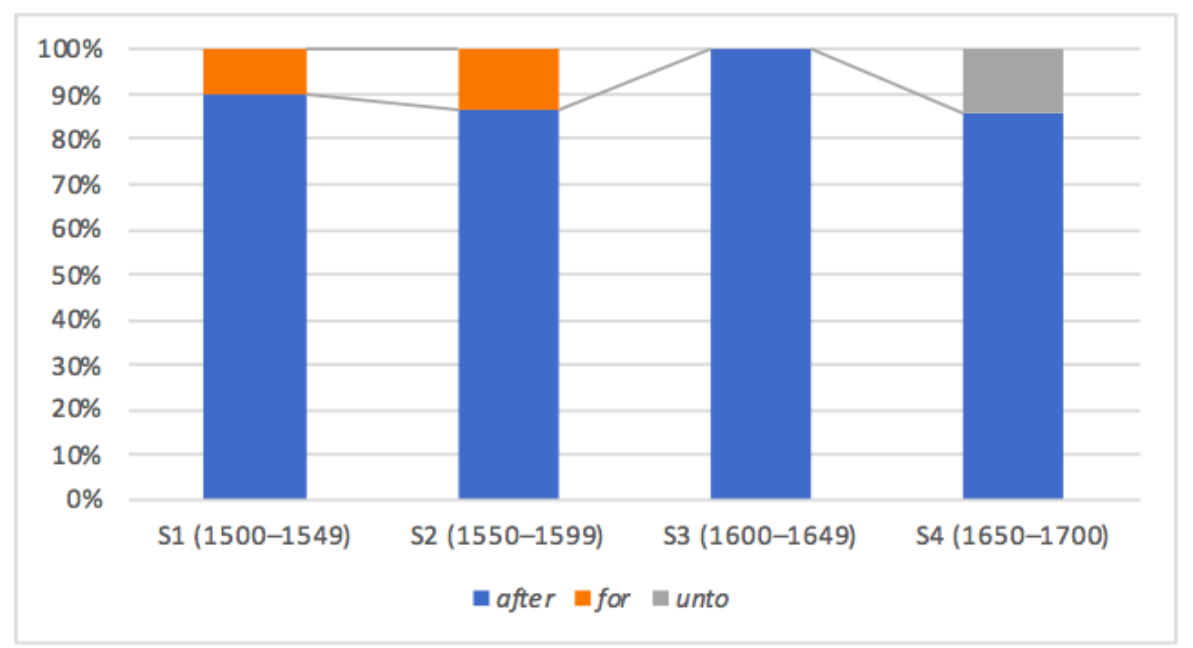

Figure 3: Diachronic distribution of prepositions governed by EModE lust (relative frequencies)

(22) 1543. yf my harte hathe lusted after my neyghbours wyfe. (D00000998461650000.txt)

(23) 1548. For we begynne to couet and lust for pleasant thynges, lo g before we know whether God wyll gyue them vnto vs, or no. (D00000998449220000.txt)

(24) 1675. This the Apostle intends by its being present with us; it is present with me, that is, alwayes, and for its own end, which is to lust unto sin. (D00000093786480000.txt)

\subsubsection{Patterns with NP complements}

In patterns with NP complements, a nominal or pronominal argument in the subjective case expresses the semantic role of EXPERIENCER, and an NP complement expresses the semantic role of CAUSE. According to the OED, this pattern is found with lust only in the seventeenth century (see OED s.v. lust, v. $\dagger 3 . \dagger$ d.).

In the EModE data, CAUSES are nominal in all cases (6 tokens; examples (25)-(27)).

(25) 1536. he forbade to lust and couet another mannes wyfe in thy harte. (D00000998400370000.txt)

(26) 1546. for these were lyght enoughe to beare, lyghter and easyer then to not luste or desyre any thynge agaynst goddes wyll. (D00000998386180000.txt) 
(27) 1548. For who soeuer lusteth or desyreth in herte any thyng whiche is his neyghbours, is condemned by the law. (D00000998447910000.txt)

In example (25) the verb lust is coordinated with the near-synonymous verb covet 'to desire'. In patterns with NP complements the verb occurs in coordination with another verb in 3 out of 6 instances, including the verbs covet (one token; example (25)) and desire (2 tokens; examples (26) and (27)), both of which are amply recorded with NP complements in EModE (see OED s.v. covet, v. 1. a. and desire, v. 1. a.). Lust has also been found in combination with a PP adjunct headed by against in (26) (2 tokens), which is analogous to the PP adjuncts frequently found in patterns with zero complements.

NP complements with lust are very infrequent overall and, judging from the historical evidence available, they developed during the EModE period probably as an alternative to patterns with a prepositional complement for the (pro)nominal expression of the CAUSE. NP complements, however, seem to have been rapidly dismissed, probably due to the fact that CAUSES do not show any of the Proto-patient properties postulated by Dowty as contributing to the syntactic function of object (see Table 1). To recall from Section 3, CAUSES do not undergo a change of state (Property 1), they are not an incremental THEME (Property 2), they are not causally affected by another participant (Property 3), they do not lack movement relative to the position of another participant (Property 4) and they do have independent existence from the event named by the verb (Property 5). Hence, the fact that CAUSES show a low degree of affectedness (Hopper and Thompson 1980: 262) might act as a factor which makes them more eligible as prepositional than as NP complements (see Dowty 1991: 578).

\section{SUMMARY AND CONCLUSIONS}

The present case study has presented an analysis of the diachronic development of lust in the EModE period (1500-1700). The data have been analysed paying attention to syntactic and semantic factors. From a syntactic perspective, patterns have been characterised in terms of the formal realisation of arguments. From a semantic perspective, the properties of participants have been assessed in the light of Dowty's (1991) account of semantic roles.

With regard to the diachronic development of impersonal patterns, these have been recorded only in the first half of the sixteenth century. Considering that these have been 
said to decrease in frequency between 1400 and 1500 (van der Gaaf 1904: 142; Allen 1995: 441-442), with marginal instances being found until about 1600 (Möhlig-Falke 2012: 14-15), the findings in this study are in broad agreement with the general account provided in the literature.

In connection with the occurrence of impersonal patterns after 1500, Lightfoot (1979: 229) points out that "it is more accurate to date the final obsolescence [of impersonal constructions] from the mid-sixteenth century." This claim, however, is not supported by the particular case of lust, since the occurrence of this pattern into EModE is largely due to its persistence in fossilised structures like as him lusteth and when him lusteth, which do not constitute instances of real productivity of the construction. The evidence, rather, is in keeping with Traugott's (1972: 130-131) observation that sixteenth-century examples represent either "conscious archaisms" or idiomatic expressions (see also Allen 1995: 279-283; Möhlig-Falke 2012: 14-15).

As to the formal realisation of arguments, the fact that pronominal EXPERIENCERS are generally favoured with this verb may follow from the fact that they are typically human beings, and "human beings are more likely to be referred to by pronouns than are things" (Allen 1995: 333). This applies to all the personal pronouns listed in Section 6.2 except the neuter $i t$, which often (but not necessarily) has non-human reference. The overall high frequency of pronominal EXPERIENCERS may also be related to the general concern in religious discourse with the individual's thoughts and actions, which leads to human beings often becoming the topic of discourse. Worthy of mention is also McCawley's (1976: 198) observation that verbs that denote emotions are more likely to take pronominal EXPERIENCERS insofar as they denote "the 1st person's inherently subjective experience." Notice that this claim cannot be upheld in the present study in view of the fact that first-person pronouns are among the least frequent variants in the corpus (see Section 6.2 on the range of personal pronouns attested in personal use).

The examination of whether the arguments of lust are nouns or pronouns also allows us to draw some hypotheses with respect to the factors which have been claimed to affect the loss of impersonal patterns. As explained in Section 2, the reanalysis hypothesis formulated by Jespersen (1961) rests on the assumption that the SVO personal use developed from OVS sentences resembling OE pam cynge licodon peran, where there are two nominal NPs representing the roles of EXPERIENCER and CAUSE which eventually became morphologically ambiguous due to the loss of case inflections. As an objection 
to this claim, Allen (1986) points out that the reanalysis cannot have started from this sentence type if we take into account that clauses with two nominal NPs were highly infrequent in ME data for the impersonal verb like (Allen 1986: 378).

In line with Allen's argument, if ambiguous case marking had been the reason for the interpretation of EXPERIENCERS as subjects in the case of lust, we might as well expect a large proportion of examples to have two nominal NPs at the start of the EModE period, which is about two centuries after the shift to personal use is supposed to have started in the fourteenth century (see Section 5). However, the data examined in this study contain mostly pronouns for the expression of the EXPERIENCER argument, especially in S1 (see Figure 2), which are always declinable. In addition, we have seen that NO PROPs are the construction type where impersonal constructions survive the longest with this verb; it may also be remembered that NO PROPs have the EXPERIENCER realised by a pronoun in the great majority of cases in both impersonal and personal use. It thus seems doubtful that the reinterpretation of EXPERIENCERS as subjects in NO PROPs was triggered by the ambiguity caused by a lack of case distinctions.

However, it needs to be pointed out that formal ambiguity does not seem to be a possibility in EModE, since the fixation of word order was already well advanced at the time (see Section 2). Nonetheless, the EModE data show that the syntactic scenario which may have led to ambiguity in the preceding centuries is not frequent either. In view of this, it might be fruitful to carry out a study of (late) ME data in future work in order to ascertain whether morphological ambiguity did in fact arise as the verb shifted to personal use, and while word order was not as yet rigidified.

All in all, the evidence gathered in this study shows that the EModE period witnesses crucial changes in both the meaning and the argument structure of lust. In the sixteenth and seventeenth centuries not only does the verb undergo a process of semantic specialisation (see Section 1), but syntactically it also becomes less frequent in patterns with clausal complements. At the same time, zero complements become surprisingly common, which may be accounted for by the frequency of idiomatised expressions typical of the religious domain where lust is most common. On the other hand, NP complements are only rarely found, leaving room for prepositional complements to become the preferred alternative for the expression of (pro)nominal CAUSES, in accordance with the PDE use of this verb. Lastly, it is also interesting to note that the development of prepositional patterns ties in with the development of other (im)personal 
verbs of DESIRE, such as hanker (after), long (for), thirst (after) or yearn (for), which similarly joined the prepositional class of verbs in PDE (Levin 1993: 194-195).

\section{REFERENCES}

Allen, Cynthia L. 1986. Reconsidering the history of like. Journal of Linguistics 22/2: 375-409.

Allen, Cynthia L. 1995. Case Marking and Reanalysis: Grammatical Relations from Old to Early Modern English. Oxford: Clarendon Press.

Anthony, Laurence. 2019. Antconc (version 3.5.8). Tokyo, Japan: Waseda University. https://www.laurenceanthony.net/software/antconc/

Barber, Charles. 1997. Early Modern English (second edition). Edinburgh: Edinburgh University Press.

Bybee, Joan. 2010. Language, Usage and Cognition. Cambridge: Cambridge University Press.

Croft, William. 1991. Syntactic Categories and Grammatical Relations: The Cognitive Organization of Information. Chicago: University of Chicago Press.

Dowty, David R. 1991. Thematic proto-roles and argument selection. Language 67/3: 547-619.

Early English Books Online Corpus 1.0, compiled by Peter Petré. 2013. https://lirias.kuleuven.be/handle/123456789/416330

Elmer, Willy. 1981. Diachronic Grammar: The History of Old and Middle English Subjectless Constructions. Tübingen: Niemeyer.

Fischer, Olga and Frederike C. van der Leek. 1983. The demise of the Old English impersonal construction. Journal of Linguistics 19/2: 337-368.

Fischer, Olga, Ans van Kemenade, Willem Koopmann and Wim van der Wurf. 2000. The Syntax of Early English. Cambridge: Cambridge University Press.

Görlach, Manfred. 1993[1991]. Introduction to Early Modern English. Cambridge: Cambridge University Press.

Hopper, Paul J. and Sandra A. Thompson. 1980. Transitivity in grammar and discourse. Language 56/2: 251-299.

Jespersen, Otto. 1961[1927]. A Modern English Grammar on Historical Principles. Part III: Syntax. London: George Allen and Unwin.

Levin, Beth. 1993. English Verb Classes and Alternations: A Preliminary Investigation. Chicago: University of Chicago Press.

Lexico's Dictionary. https://www.lexico.com/en

Lightfoot, David W. 1979. Principles of Diachronic Syntax. Cambridge: Cambridge University Press.

McCawley, Noriko A. 1976. From OE/ME 'impersonal' to 'personal' constructions: What is a 'subject-less' S? In Sanford B. Steever, Carol A. Walker and Salikoko S. Mufwene eds. Papers from the Parasession on Diachronic Syntax. Chicago: Chicago Linguistics Society, 192-204.

Méndez Naya, Belén and María José López Couso. 1997. What is really meant by impersonal? On impersonal and related terms. Atlantis. Journal of the Spanish Association for Anglo-American Studies 19: 185-192.

Middle English Dictionary. 1952-2001. Hans Kurath, Sherman M. Kuhn and Robert E. Lewis eds. Ann Arbor: University of Michigan Press. Online edition available at the Middle English Compendium. 2000-2018. Frances McSparran et al. ed. Ann 
Arbor: University of Michigan Library. https://quod.lib.umich.edu/m/middleenglish-dictionary/dictionary

Miura, Ayumi. 2015. Middle English Verbs of Emotion and Impersonal Constructions: Verb Meaning and Syntax in Diachrony. Oxford: Oxford University Press.

Möhlig-Falke, Ruth. 2012. The Early English Impersonal Construction: An Analysis of Verbal and Constructional Meaning. Oxford: Oxford University Press.

Oxford English Dictionary Online. https://www.oed.com

Traugott, Elizabeth C. 1972. A History of English Syntax: A Transformational Approach to the History of English Sentence Structure. New York: Holt, Rinehart and Winston.

Trousdale, Graeme. 2008. Words and constructions in grammaticalization: The end of the English impersonal construction. In Susan M. Fitzmaurice and Donka Minkova eds. Studies in the History of the English Language IV: Empirical and Analytical Advances in the Study of English Language Change. Berlin: Mouton de Gruyter, 301-326.

van der Gaaf, Willem. 1904. The Transition from the Impersonal to the Personal Construction in Middle English. Heidelberg: C. Winter.

Visser, Fredericus T. 1963. An Historical Syntax of the English Language. Part 1, Syntactical Units with one Verb. Leiden: E. J. Brill.

Corresponding author

Noelia Castro-Chao

Campus Norte · Av. de Castelao s/n

15782 Santiago de Compostela

e-mail: noelia.castro.chao@rai.usc.es

received: August 2019

accepted: October 2019 